\title{
Key progress on the filling mining of deep resources in Jinchuan Nickel Deposit
}

\author{
Zhiqiang Yang National Key Laboratory for Comprehensive Utilization of Nickel and Cobalt Resources \\ Jinchuan Group Co, Ltd, China
}

\section{Abstract}

On the basis of resource endowment and geological features, harsh geological conditions and mining environment for the effective mining and comprehensive utilization of deep resources in Jinchuan Nickel Deposit were systematically analyzed, including high stress, fragmentized ore rock, prevalent deformation, difficult support, complicated rock mechanics and low mining recovery. An integrated technology package has been established for safe, efficient and continuous mining at the huge, complex and deep nickel and cobalt mine by proposing a large-area continuous mining method with honeycomb drives and establishing ground control theory and technology package in high stress and fragmented ore rock, and by developing new backfilling cement material and deep backfilling technology with pipeline transport of high density slurry with coarse aggregate, in order for an efficient exploitation and comprehensive utilization of deep resources in Jinchuan Nickel Mine, hence presenting technological demonstration for the underground mine using cemented undercut-and-fill mining method with stressful, fragmented and rheological rock.

\section{Introduction}

Discovered in 1958, Jinchuan Nickel Mine is a world renowned multi-metal sulfide composite deposit, containing a variety of symbiotic elements, among which nickel and copper are dominant. Lying at the foot of Mount Longshou, it is $6.5 \mathrm{~km}$ long and $500 \mathrm{~m}$ wide. The proven reserve is 560 million tons, with 6.03 million tons of nickel, 3.89 million tons of copper, and more than 20 valuable elements such as cobalt, silver and platinum group metals, ranking the third in size internationally. The deposit plays a vital role in nonferrous metal resource structure in China with its nickel reserve accounting for $79 \%$ of the total, cobalt ranking the second, and platinum group metals topping the reserve list, accounting for more than $80 \%$ of the domestic reserve in China (Nonferrous Metal Corporation, 1996). However, this mine also features complicated mining conditions, with well-developed joint fissures and deep-buried ore bodies caused by a number of tectonic movement. Furthermore, the mine is rare with high stress, large scale and difficult mining conditions, such as high ground stress, fragmented ore rock, massive deformation, difficult support and complex rock mechanics.

At present, the Jinchuan Mine has entered deep mining as the operation is over 1,000 $\mathrm{m}$ beneath the surface. With a total mining area of over $570,000 \mathrm{~m}^{2}$, the geological conditions are deteriorating, featured by increasing mining area, more fragmented ore rock, more developed joint fissure and higher ground stress. Serious deformation and rheology are causing instable stope wall rock and tunnels, increasingly challenging the deep mining operation at Jinchuan Nickel Mine and leading to higher risks of geological disasters.

Mining experiences of deep metal mines have shown that conventional theories and methods may not be suitable for deep mining because of special conditions including high ground stress, temperature, seepage pressure and complicated geological features. Compared with shallow mining, deep mining is not only 
challenged by high ground stress and difficult support but also faced with issues such as personnel and equipment safety, deterioration of working conditions, low productivity, high mining cost and operation over large area (He, 2005). Therefore, the exploitation and utilization of the resources deep in the mines needs to be given particular attention so as to achieve the efficient, safe and economical mining.

To that end, the resource endowment and geological characteristics needs to be systematically studied for a safe, efficient, economical, and environmental-friendly exploitation and utilization of the resources deep in the Jinchuan Mine. A technology package for continuous deep mining and backfilling is proposed through theoretical guidance, technological research, operation practice, process improvement, system integration and information sharing, which has profound significance for the mining of deep resources at Jinchuan Mine.

\section{Resource endowment and geological features}

Jinchuan deposit is located at the uplift belt of Mount Longshou at the edge of Alxa platform block. It is south to a tidewater basin and north to the geosyncline of Mount Qilian. Due to the tectonic movements since Lvliang Movement, tectonic signs could be found in well-developed factures of various shapes. Two deep and large faults can be found at each side of the uplift belt of Mount Longshou, with the one on the north called Fault F1 (He, 2005).

Ore-bearing rock mass at Jinchuan deposit is $6,500 \mathrm{~m}$ long and 20 to $527 \mathrm{~m}$ wide, with a depth ranging from several hundreds of meters to over 1, $100 \mathrm{~m}$ (see Figure 1). Both eastern and western sides are covered by quaternary, with outcrops in the middle and denudation on the top. The rock mass strikes northwest at $50^{\circ}$ and inclines southwest at 50 to $80^{\circ}$. It is divided into four sections from west to east, named as No.3, 1, 2 and 4 mining area.

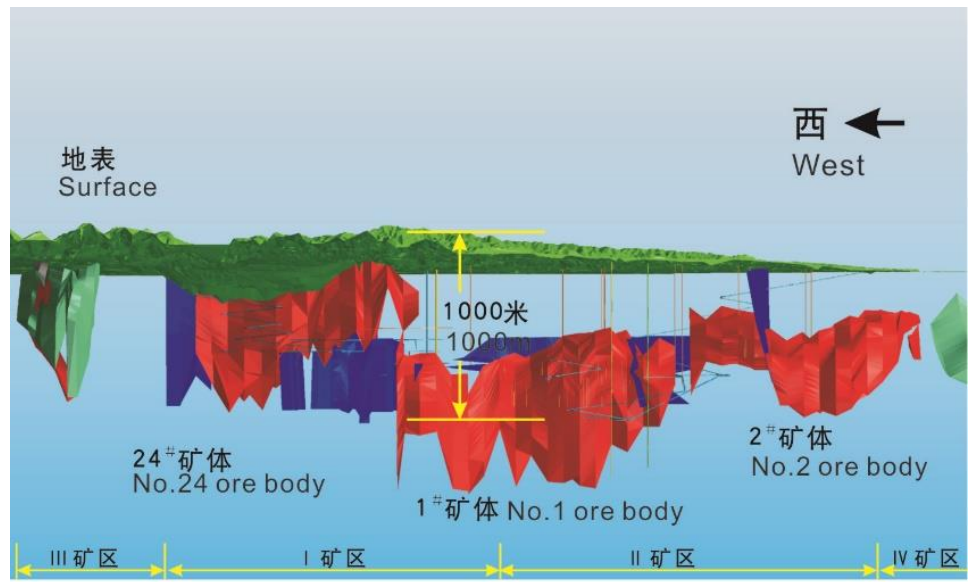

Figure 1 Jinchuan deposit model based on SURPAC

The outcrop stratum at Jinchuan deposit is mainly the Pre-Sinian Baijiazuizi group mesometamorphic rock, including banded migmatite, chlorite quartz schist, serpentined marble, marble with agmatite, pomegranate mica gneiss and biotite plagioclase gneiss. The stratum inclines to southwest.

In addition to ultramafic rock, there also exist pinkish red granite and alaskiteand ultramafic induced dikes such as aplite, diabase, lamprophyre and fine-grained diorite, etc.

Ore-bearing ultrabasic rock mass intrudes into marble and migmatite as irregular dikes, with main lithofacies being dunite, pyroxene peridotite, Iherzolite, plagioclase Iherzolite and pyroxene. And the first three are dominant ore-bearing lithofacies. Distribution of rock has obvious control over mineralization.

(1) The mine features complicated tectonic movements and high tectonic stress. The strata have experienced a number of geotectonic movements and the metamorphism and multiple intrusion of magma since the Lvliang Movement (as shown in Figure 2). The lower Proterozoic metamorphic rocks 
show multi-period deformation, metamorphism and strong tectonic replacement, indicating fierce transformation and mutual superposition. Magmatic rock such as ore-bearing ultramafic rock was transformed into lentoid structure during a series of deformation and metamorphism after magma period, resulting in extreme development of tectonic fractures and joints. The ore rock showed poor stability due to frequent cutting of soft structural planes (e.g. fault planes, inter-fault compressive planes, and joints) and complex rock combinations. The stability was further weakened by the existence of serpentine, tremolite and chlorite schist zone at the contact area between orebody and surrounding rock, causing the expansion, dilatancy and creep by the argillization of fragmented rock mass (Nonferrous Metal Corporation, 2000).

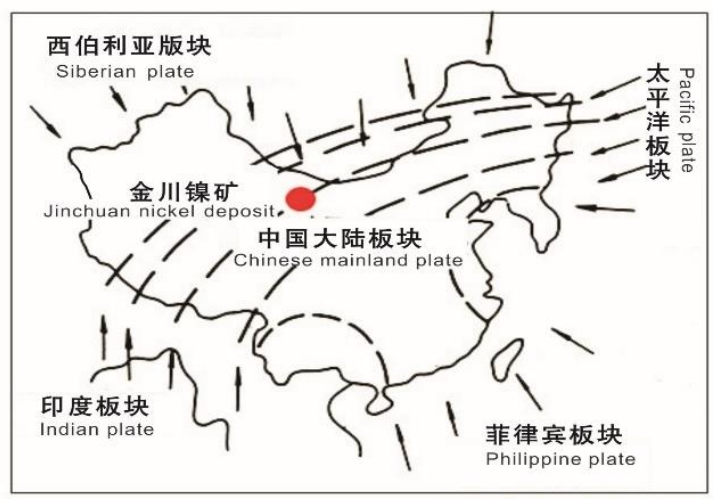

\section{Figure 2 Trace chart of plate effect on Jinchuan nickel deposit}

Due to the repeated tectonic superposition, traction and transformation, the tectonic stress in Jinchuan Nickel Deposit is high, complicated and diversified. Horizontal tectonic stress prevails deep in the mine, and increases linearly with depth. Generally around 30 to over $50 \mathrm{MPa}$, it falls within the range of mid-high to super-high stress, closely related to tectonic denudation. Both the vertical original rock stress caused by gravity and horizontal stress caused by excavation increase dramatically. Meanwhile, according to the ground stress from site monitoring at depth, deep rocks present obvious traces of ancient tectonic movements. And the congruence of tectonic and residual tectonic stress field resulted in anisotropy and inhomogeneity in the ground stress field of deep rock mass. Compared with the mine area closer to the ground surface, the maximum principal stress at depth deflected and its angle with horizon increased, leaving deep stopes and their surrounding rock in an unfavorable stress environment (Engineering geology and rock mechanics for super-large nickel mine 2013).

(2) The total amount of resources in Jinchuan deposit is high, with a low average grade (that of nickel is $0.96 \%$ ) and numerous associated valuable elements worth of extracting. However, the retaining resources are highly concentrated, with the low grade ore accounting for a large proportion, making the full utilization of the resources difficult.

(3) The Jinchuan deposit is vast and deeply buried. Previously, large area pillar-free continuous mining and mechanized cemented undercut-and-fill mining were adopted, leaving an extra-large mining area of $570,000 \mathrm{~m}^{2}$. Intensive large area mining and blasting greatly affected the stope stability. As deep mining continued and mining scale increased, an increasingly amount of surrounding rock had their stress status and inherent properties changed by the mining activities. Furthermore, large area mining at multiple-echelon model activated the stress, causing the rock stress to increase by several or even 10 times around various excavating operation already under high ground pressure and hence deteriorating the mining conditions. 


\section{Key technological problems for mining at the depth of Jinchuan}

\section{Mine}

As a large-scale mine with resources difficult to exploit, Jinchuan Nickel Mine features complex geology, unique resource endowment, special engineering conditions, rock mechanics of broken expansion and rehology, high ground stress, as well as deep-buried and unstable ore bodies. Therefore, a considerable number of studies have been conducted on mining and rock mechanics to address the following technical issues so as to ensure the effective exploitation of resources buried deep in the mine.

(1) Control of broken expanded rock under high ground stress: with high ground stress in Jinchuan Mine, the surrounding rock of deep roadways shows obvious crack-expansion creep and frequent ground pressure activities. The design of deep mining layout is key to revealing distribution law and emergence mechanism of the complicated ground stress, and to scientifically assessing the quality of deep surrounding rock and dividing the stability of the ore rock. It is the main theoretical basis for rock stability control to understand the deformation and failure mechanism of deep surrounding rock and to clarify the impact mechanism of mining on rock failure. It is also the premise of efficient and safe mining operations to set up a dynamic monitoring system on deformation across the mine and to develop a stope disaster forecast system.

(2) High intensity mining with high productivity and recovery in thick, inclined and deep ore bodies: The Jinchuan Mine is characterized by fragmented ore rock, well-developed joints and sophisticated stress. Innovative and efficient mining methods need to be developed to ensure the implementation of pillar-free continuous large area stoping in thick and inclined ore bodies, the realization of continuous mining in deep ore bodies and uniform descending of multiple echelons. Mining and backfilling also needs to be balanced to increase mechanization and automation for higher mining rate and lower dilution rate, and to realize efficient mining at low cost.

(3) Continuous stoping in large area: cemented undercut-and-fill mining is adopted in Jinchuan deposit. As mining depth increases, the world's biggest backfill body in a metal mine has taken shape in Jinchuan Mine. Its overall stability and deformation has posed potential geological risks deep in the mine. In addition, due to the intricacies of high density slurry cemented backfilling for deep mining, there follows a number of problems, such as the difficult transportation of high density slurry, poor system stability, complicated layout of backfilling pipelines and severe wear of backfilling drill holes and pipelines. In order to achieve efficient deep mining, it is also key to optimizing the composition of high density backfilling slurry, ensuring the stability and reliability of the backfilling system, and to making the backfill strength compatible with continuous mining of thick ore bodies.

(4) Comprehensive utilization of mineral resources: Jinchuan deposit features low average grade, high content of magnesium oxide and strong alteration on the one hand, and a number of valuable elements worth extracting on the other hand. It is of great significance to develop lean ore at No. 3 and No. 4 mining area to operate low cost mining at higher overall recovery, innovate mining and mineral processing, improve technical and economic indexes for extracting nickel, cobalt, copper and associated elements, and to make full use of tailings and smelting slag in an economical and environmental friendly way for circular economy.

(5) Prevention of geological disasters in deep mining: It is generally considered that surface rock movement in metal mines is not serious with backfilling mining, with massive geological disasters unlikely to be induced. However, in Jinchuan Mine, large area rock movement, deformation and failure have taken place at ground surface despite the use of high density cemented backfilling. As 
mining depth and scale increase, the prevalent rock movement, deformation and building failure at surface have taken place, posing huge threats to mine stability and shaft security. The mining depth in Jinchuan is over $1000 \mathrm{~m}$, with a total mining area of over $570,000 \mathrm{~m}^{2}$. Deformation captured by GPS monitor shows that surface rock movement roughly centers on the major underground mining area, with slight acceleration of the deformation rate of surface rock movement and development of surface tension cracks. Line 14 ventilation shaft, located at the rim of subsidence basin of the No.2 mining area, has experienced a vertical subsidence of $1,070 \mathrm{~mm}$, horizontal movement of $455 \mathrm{~mm}$ and 3D movement of 1,185 mm since it was rebuilt 15 years ago in 2005 after it collapsed. Monitoring data show that extensive surface rock movement has posed a major threat to the underground mining and surface facilities. Therefore, huge challenges have been posed to monitor deformation in surrounding rock and backfill, study and establish the relationship between underground mining intensity and surface rock deformation, and establish a scientific forecast system for mine disaster and stability failure.

\section{Key research direction and phased results of deep resource exploitation}

\subsection{Theory and technology on broken expanded and rheological rock under high stress}

\subsubsection{Distribution law of ground stress in Jinchuan Mine}

Much attention has been paid to the investigation of ground stress law at Jinchuan Mine, with a number of research having been conducted to measure and monitor stress in terms of multiple phases, echelons, locations and methods. Stress distribution regression function was determined by statistical analysis, leading to a primary understanding of the stress distribution law at Jinchuan Mine. The stress prediction and regression results are shown in Figure 3.

Analysis of stress deep in the mine shows that the maximum principal stress, maximum and minimum horizontal principal stress varied to the third power with depth, while the vertical stress increased linearly with depth; a huge gap existed between the maximum and minimum principal stress; direction of the maximum deep principal stress deflected and increased in the angle to horizon, indicating higher shear stress at depth and weakening the stability of deep ore rock(engineering geology and rock mechanics for superlarge nickel mine 2013).

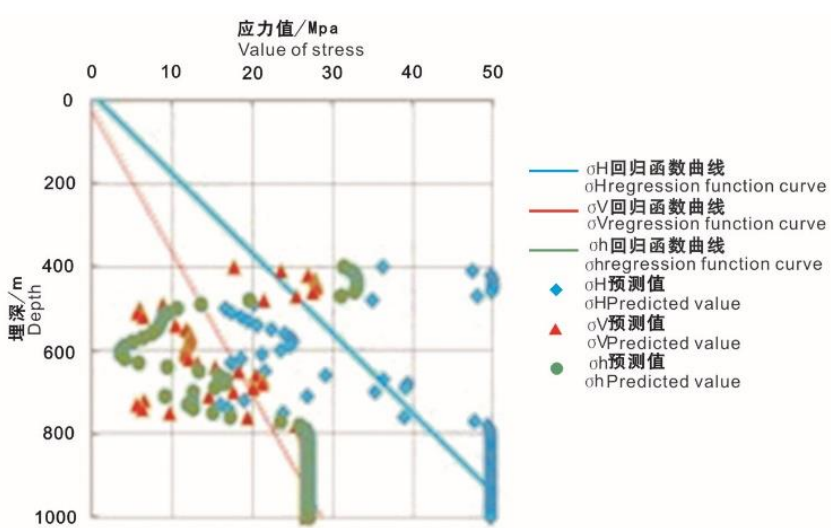

Figure 3 Stress $\sigma \mathrm{H}, \sigma \mathrm{h}$ and $\sigma \mathrm{V}$ vary to the depth

\subsubsection{Mechanism of deformation and failure in deep surrounding rock}

Rock stability in Jinchuan Mine depends mainly on ground stress environment, engineering geological 
conditions, rock mechanics and mining impact. Rock mechanical tests over the years show that the dominant deformation mechanism of jointed rock mass under stress included unloading spring-back, dilatancy, crash creep and water-absorbing expansion of surrounding rock, with enormous and rapid deformation, long lasting, pressure from all directions and obvious shrinkage deformation (as shown in Figure 4 and Figure 5). Depending on the mine-induced stress, the deformation of surrounding rock increases in stages with time and without convergent trend. Generally, the decrease of deformation rate fluctuates, but never to zero. The critical value for rock rheology was defined as 3.0 MPa by analyzing the rheological characteristic of surrounding rock in Jinchuan Mine. When the stress exceeded 4.35 MPa, rheology of ore rock accelerated. In the meantime, stress and strain tests of rock mass showed that accumulated plastic deformation increased dramatically as cyclic loading increased. When the stress was $7.16 \mathrm{MPa}$, residual deformation accounted for two thirds of the total deformation.
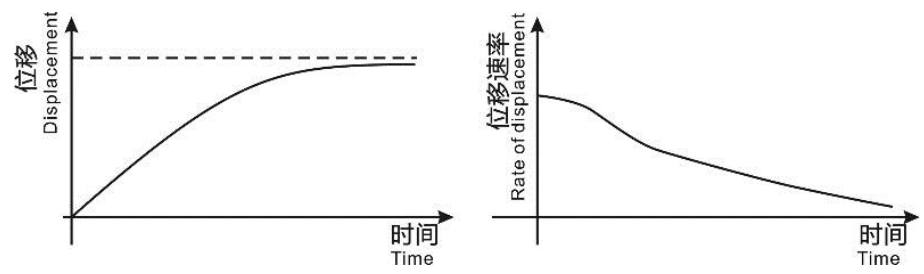

Figure 4 Permanent engineering deformation-time curve and rate-time curve in non-dynamic pressure
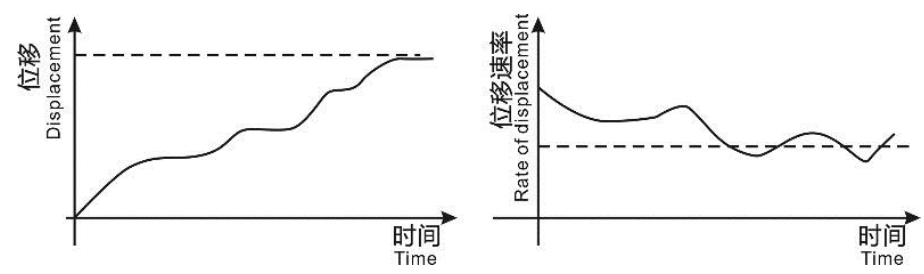

Figure 5 Engineering deformation-time and rate-time curves in dynamic pressure roadways

\subsubsection{Deformation monitoring and disaster predicting and pre-warning system}

Based on the surface GPS network (as shown in Figure 6) and distributed optical fiber sensing, a stereo dynamic deformation monitoring system has been set up across Jinchuan Mine, and a disaster predicting and pre-warning system has been developed.

Distributed optical fiber was adopted in Jinchuan Mine to monitor the deformation in the surrounding rock of stopes and backfill. An equivalent intelligent numerical model was set up according to the monitoring data. The model was based on the equivalent mechanical parameters of the stope surrounding rock in Jinchuan Mine by using 3D orthogonal numerical tests and genetic programming algorithm to establish the relationship between surface rock movement and rock mass parameters. The sum of the square of the difference between the monitored and calculated value is examined to optimize the model by minimizing the sum.

$$
M \text { in } F(x)=\sum_{i=1}^{n}\left[f_{i}(x)-w_{i}\right]^{2}
$$

In the equation, $F(x)$ is a pattern recognition optimization function, $\mathrm{fi}(\mathrm{x})$ is the calculated value of movement in the model in relation to point $i$, and $w_{i}$ is the measured value of movement relating to point $i$. Equivalent rock mass parameters were obtained by solving the equation for the current mining stage (correspondent monitoring deformation), and then the model verification and reliability assessment was conducted (as shown in Figure 7); finally, the stope stability analysis and rock movement prediction was carried out. A system was developed for data management of deformation monitoring, assessment of rock stability, and disaster predicting and pre-warning, hence providing support for mining design and safe production. 


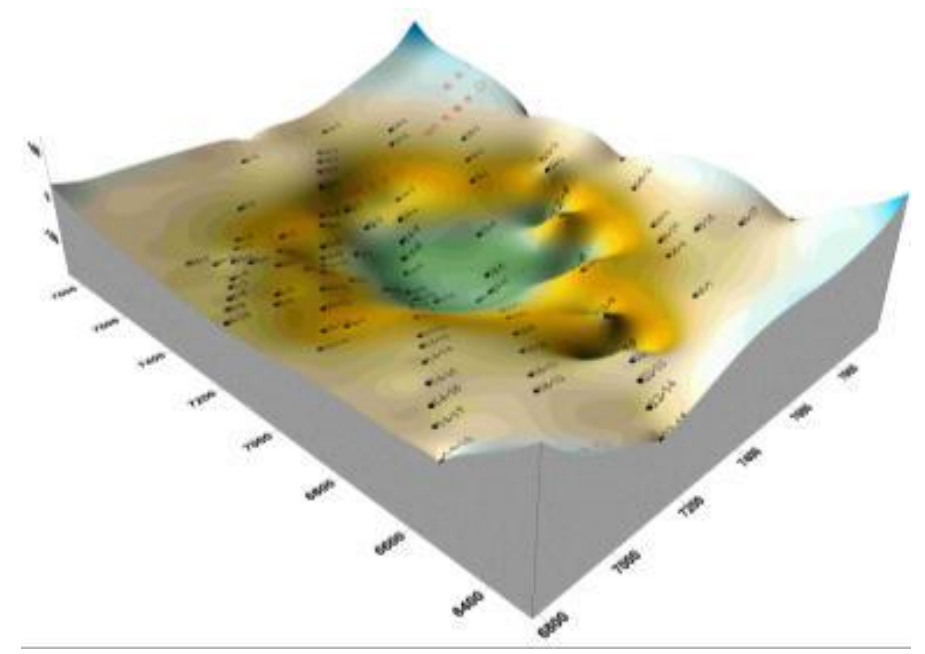

Figure 6 3D graph of surface subsidence measured by GPS

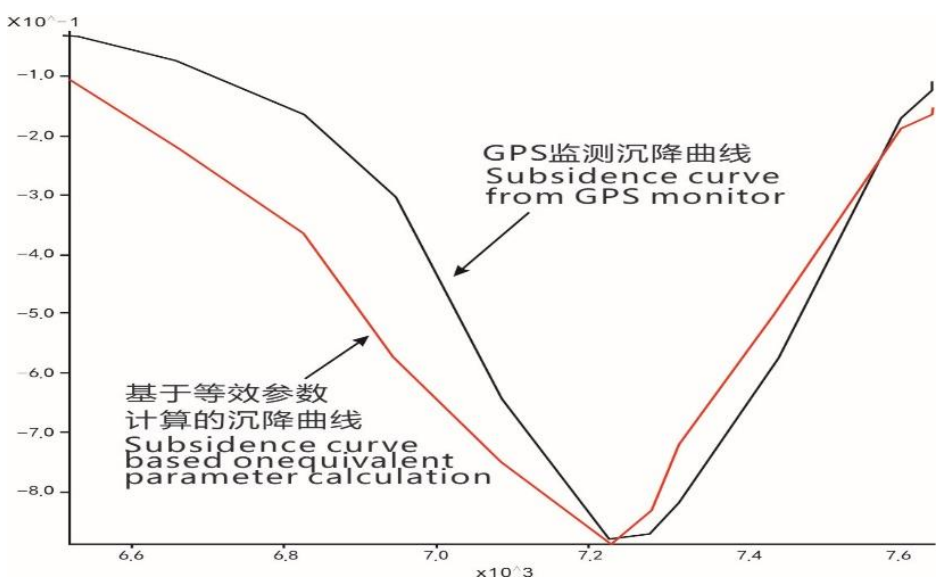

Figure 7 Comparison of displacements from equivalent intelligent model calculation and GPS monitor

\subsubsection{Support technique for surrounding rock in deep roadways}

Unimpeded and stable tunnels are important for safe and efficient deep mining in Jinchuan Mine. Theoretical calculation, numerical modeling and on-site tests were systematically carried out on support technology, designing method, support materials, operating techniques and effect appraisal by comprehensively studying the deformation mechanism, failure features and de-stability model in deep surrounding rock. New breakthroughs were made in deep tunnel support.

The deformation characteristics and de-stability model of the stressful and fragmented rock in Jinchuan Mine were studied, with the following techniques proposed for effective controlling of ground pressure activities and roadway deformation:

- Joint control technique for deep repairing tunnel grouting and support loading: Surrounding rock in repairing tunnels was groutable for cement slurry with the water-to-cement ratio of 1:1. Reasonable grouting parameters include a grouting pressure of 2.0 3.0 MPa, one or two wall back grouting holes at every meter of the tunnel, one meter of row distance and $2 \mathrm{~m}$ of depth for grouting holes, and the grouting cemented volume accounting for $1 \sim 1.5 \%$ of that of the reinforced rock. Engineering practices show that backfilling behind support and grouting layer could evenly pass the stress in surrounding rock onto support structure, preventing the concentration of stress on the structure. Furthermore, elastic backfilling layer can release a certain amount of deformation pressure, avoiding huge deformation in the surrounding rock. 
- Flexible support technique by grid steel arch bolting and shotcreting: Support resistance is required shortly after the roadway excavation in weak rocks in order to protect the backfill from passive compression. The originally flexible and soft grid steel arch bolting and shotcreting mesh becomes rigid and resistant which can close the surrounding rock timely and adjust and maximize the selfbearing ability of surrounding rock. As it fits with the rapid pressure movement, huge convergence deformation and strong rheology in the surrounding rock, it is the dominant method of support in deep tunnels at Jinchuan Mine. By this technique, blasting parameters for smooth blasting are first optimized to ensure the excavation of the tunnel is in line with its design. The space of grid steel arches is defined as $800 \sim 1,200 \mathrm{~mm}$, followed by the erection of grid steel arches, installation of metal mesh and wet shotcreting, and the final reshooting of the concrete used to thicken the grid steel arches far away from the tunnel face. The experiment has shown that the repairing rate of tunnels decreased from 35 to $20 \%$.

\subsection{New technique of large-area continuous mining in honeycomb structure drives}

\subsubsection{The technique of pillar-free large area continuous stoping of thick ore bodies}

As mining depth increased in Jinchuan Mine, lensoid thick ore bodies gradually expanded the mining area. If interval pillars were left between panels, stress would concentrate on the pillars for a long time with the peak stress up to $447.94 \mathrm{MPa}$, according to the numerical simulation analysis. This left the pillars in stressful plastic areas and would cause severe damage, leading to difficult two-step recovery of the pillars.

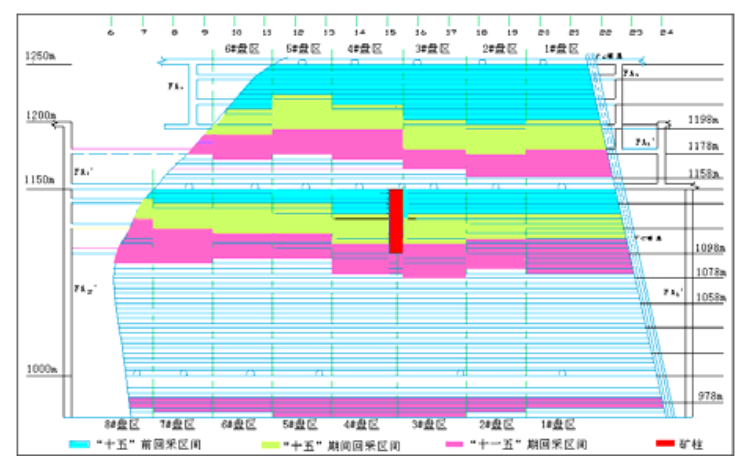

Figure 8 Pillar-free large area continuous mining method

Given the stress distribution of deep thick ore bodies and ground control technology, the technique of pillarfree large area continuous stoping was developed (see Figure 8) on the basis of the conventional two-step mining model. Echelons were 100 to $150 \mathrm{~m}$ high, and sub-levels and layers were 20 and $4 \mathrm{~m}$ high respectively. Echelons and sub-level were connected by declines and mining panels were divided along ore body strike, with no panel pillars left. Mining was conducted in drives within panels, with drives arranged in line and blocked by ore rock. Drives were backfilled one by one as soon as mining was finished. Hanging wall and surrounding rock were supported by backfilling and to-be-mined ore bodies, realizing continuous stoping of ore bodies and higher mining efficiency in panels.

\subsubsection{Large section hexagonal drives with honeycomb structures}

Stope drives were arranged in a honeycomb structure based on the bionics principle. Honeycomb structure arranges the equilateral hexagons with no space among them. With maximal loading capacity and minimal peripheral area, a hexagonal prism features good structural stability.

Hexagonal drives were arranged in a honeycomb structure, making both the drive section and backfill section in a honeycomb shape and realizing non-space layout among equilateral hexagons. Stress concentration was reduced effectively, and support ability of surrounding rock was fully exploited, producing favorable rock 
stability. However, at the early stage of experiment, the production capacity of stopes was constrained by structure and design parameters of hexagonal drives and blasting technique. Based on the calculation of 3D finite element model (3D- $\sigma$ ), the mining method features large section hexagonal drive with honeycomb structure (as shown in Figure 9) was innovated by analyzing the backfill stability in terms of stress distribution, deformation rate and plastic zone distribution. Structure parameters of hexagonal large sections were optimized to be $3.5 \mathrm{~m}$ wide at the bottom, $7 \mathrm{~m}$ wide at the waist, $6 \mathrm{~m}$ high at the section, and $31.5 \mathrm{~m}^{2}$ large a section area (an increase of $40 \%$ ) which significantly improved the efficiency and production capacity of the stopes. Stress conditions around stopes were remarkably improved, with the maximum principal stress decreasing from 93.48 to $47.19 \mathrm{MPa}$, according to the numerical simulation calculation, and stress concentration factor being $50 \%$ lower than that of the square drives. Roof and sidewall failures in drives were reduced dramatically and stope maintenance cost was cut by $30 \sim 50 \%$.

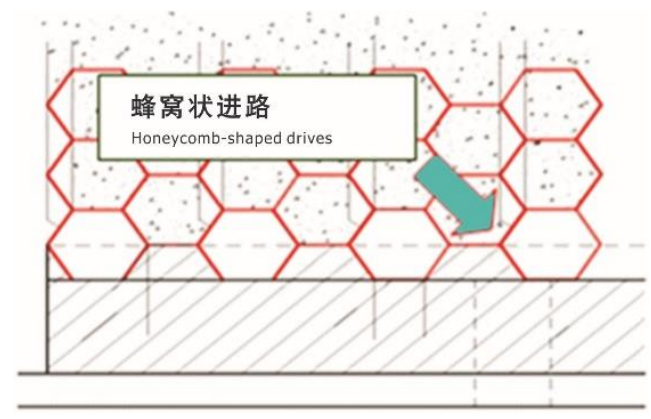

Figure 9 Large section hexagonal drive mining method

\subsubsection{Large-diameter empty-hole spiral cutting blasting}

Architectonic characteristics of fragmented ore rock and developed joint fissure presented huge challenges for drilling and blasting in Jinchuan Mine and restrained the further development of mining capacity. The forced state and throwing law of rock in empty-hole blasting was examined, revealing the mechanism of spiral cutting blasting. A spiral cutting hole arranging principle was proposed based on the relationship between free face width and optimal resistance line. The increasing order of the distance from charging hole to empty hole was determined, and the large-diameter empty-hole spiral cutting blasting technique was developed: the distance from an empty hole to the charging hole could be 1.0 to 1.8 times, 2.0 to 3.5 times and 4.0 to 5.5 times that of the empty-hole diameter. Asymmetric hole arrangement and millisecond detonating were conducive to cutting formation. Blasting footage of each cycle was lifted by $12 \%$, and blasting efficiency was over $90 \%$, with the section profile of drives under good control, creating favorable process and technical conditions for tunnel support, mining and backfilling operation.

\subsubsection{Optimization of stope arrangement in thick ore bodies}

Panel is the basic mining unit at Jinchuan Mine. Initially, stoping design in panels was single vein-crossing drifts, featuring disadvantages of poor safety, long stoping-backfilling cycles, great resistance to ventilation and low equipment efficiency. The design was then improved to be double vein-crossing cyclic slice drifts (as shown in Figure 10). To-be-mined area was divided into blocks for independent or combined stoping for much higher efficiency. Double vein-crossing cyclic slice drifts have improved equipment efficiency, accelerated slice switch, shortened exposure time of slice drifts and goaf and reduced the cost of secondary support for main and auxiliary vein-crossing drifts. Therefore, running efficiency of trackless equipment in panels was lifted from 88 to $96 \%$, productivity in panels by $20 \%$ and effective air flowrate by over $30 \%$. In order to improve the low mining efficiency in individual stopes, slow descending rate at upper stopes and poor coordination among stopes, a new technique of mutual mining in upper and lower stopes was developed. Slice drifts were cut and mined in advance for reasonable descending rate of stopes, higher productivity, as well as balanced mining. 


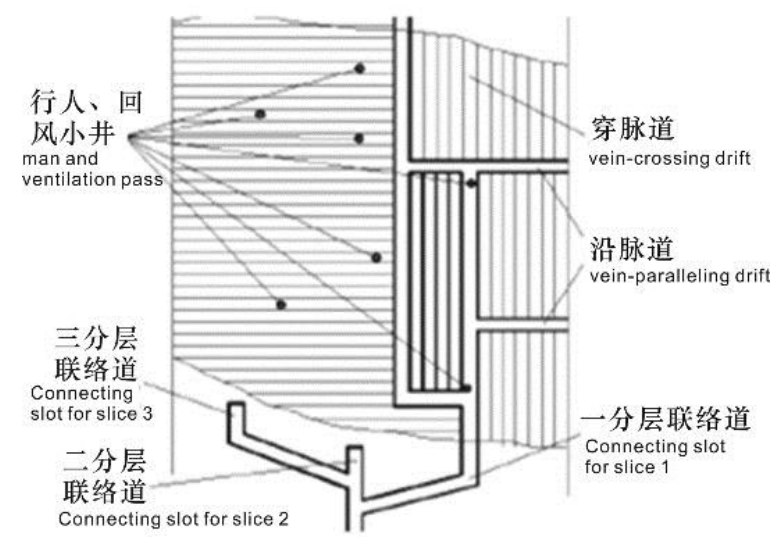

Figure 10 Cutting and mining in double vein-crossing slice drifts

\subsection{High-density slurry pipeline transport backfilling with mine solid waste as coarse aggregate}

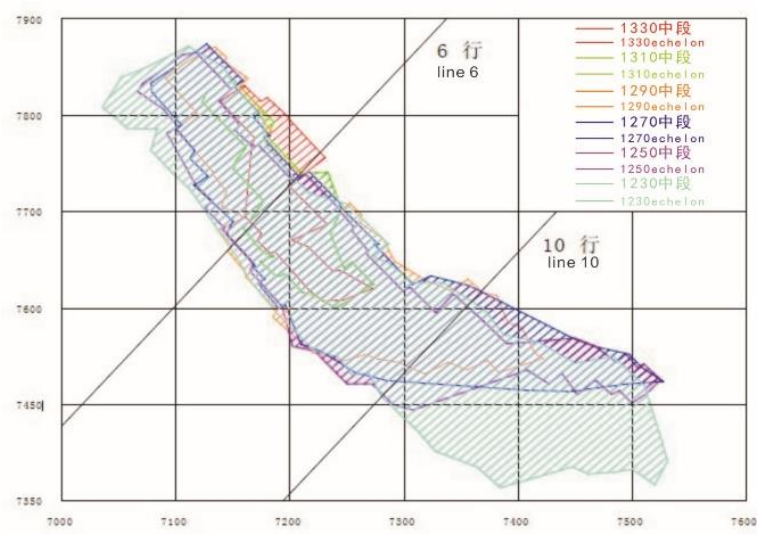

Figure 11 Goaf-side shapes at echelons

\subsubsection{Match of backfilling strength and continuous mining of thick ore bodies}

Jinchuan Mine mainly adopts the undercut-and-fill mining method which leads to huge and thick backfills over stopes. The quality and stability of backfills impact heavily on the safe stoping of ore bodies beneath them. Through extensive mining practices and test work, high density backfill slurry suitable for pipeline transportation was prepared using rod mill sand and gravel sand from Jinchuan as aggregate of the high density gravity system, optimizing backfill aggregates, cementing agents and additives and realizing a favorable match between backfilling strength and continuous mining of thick ore bodies.

Geometrical and physical properties of thick backfill were obtained from the profile of downward cemented goaf-side (see Figure 11). Structure and strength of thick backfill were examined by using the digital borehole camera, ultrasonic hole-probing and in situ backfill strength test. After consolidating and compacting for a considerably long period of time, backfill bodies joined closely without cavities or cracks, and the uni-axial compressive strength of backfilling was up to $7.8^{\sim} 11.9 \mathrm{Mpa}$, meeting the safety and production requirements.

\subsubsection{Development of high flowing slurry backfill technique with mine solid waste as coarse aggregate}

On the basis of the stacking and interstitial effects of aggregate, the stacking compactness model and optimal gradation equation were examined for several types of aggregate, providing a satisfying solution to the grade compatibility of aggregates. Gradation index was used for analyzing the gradation of rod-milling sand and slurry density to investigate the reasons for poor backfill quality despite high consumption of cement. Taking into account the ratio of aggregate to cement to moisture, a new cemented backfilling strength model equation was set up to optimize mining cost, backfilling strength and transport density: 


$$
\mathrm{R}=\alpha \Phi^{\beta}\left(\frac{W}{C}\right)^{\lambda}\left(\frac{C}{A}\right)^{\eta}
$$

Where:

$$
\begin{array}{ll}
\Phi & =\text { the stacking compactness of aggregate; } \\
\frac{W}{C} & =\text { the ratio of moisture to cement; } \\
\frac{C}{A} & =\text { the ratio of cement to sand; } \\
\alpha, \beta, \lambda 、 \eta=\text { test constants; }
\end{array}
$$

Moreover, high flowing conditions for high density backfilling slurry were suggested, which is slurry slump of over $220 \mathrm{~mm}$ and slump flow of over $450 \mathrm{~mm}$. Medium and fine particles loaded the coarse aggregate in the slurry, with fine particles fully filling the space within the coarse aggregate. Slurry in the goaf was almost selfleveling. A new technology of high flowing slurry had been developed with mine solid waste as coarse aggregate.

\subsubsection{Flowing characteristics of high density slurry and full pipe flow feeding mechanism}

Critical fluidized density was referred to as the slurry density when the density gradient vertical to the pipeline section was zero, and the mathematical model for the critical density is expressed as:

$$
M_{Z}=\left[1-16 d_{s} /\left(16 d_{s} \gamma_{k}-3 C_{s} \tau_{0}\right)\right]\left[\gamma_{k} /\left(\gamma_{k}-\gamma_{0}\right)\right]
$$

Where:

$$
\begin{array}{ll}
M_{Z} & =\text { the weight concentration of slurry; } \\
d_{S} & =\text { average particle size; } \\
\gamma_{k} & =\text { dry weight of compact backfill material in } \mathrm{kg} / \mathrm{m}^{3} ; \\
\gamma_{0} & =\text { specific gravity of water; } \\
C_{S} & =\text { shape factor of particles; } \\
\tau_{0} & =\text { initial shear stress of slurry; }
\end{array}
$$

The equation shows the relationship between critical fluidized density and parameters such as particle size of solids, initial shear stress of slurry, compact specific density of solids and transport carrier. It is obvious that both a certain density and proportion of fine particles were necessary for the preparation of slurry at critical fluidized density. Test results showed that slurry concentration was at the critical value when the optimal tailings to rod-milling sand ratio was $3: 7$ and slurry density was $77 \sim 79 \%$. The flow pattern of slurry features Herschel Black fluid model, and the coefficient of kinetic viscosity $\eta=1 \sim 2.5 \mathrm{~Pa} \cdot \mathrm{S}$. On the basis of the slurry system curve in the horizontal pipe and the pump curve in the vertical pipe, the work theory of full pipe flow feeding system with pipes of variable diameters was understood. In order to disperse residual static head produced by vertical pipes, the diameter of either vertical or horizontal pipes was reduced in order to increase the friction resistance in the section where slurry flowed, and to meet the technical requirements of backfilling operation.

\subsubsection{Failure model of backfill drill holes in deep shaft and their repairing}

The backfilling pipeline system in Jinchuan Mine is closely related to mining operations. Most of the pipelines are located in complex rock environment and dynamic excavating roadways, and the failure of backfill drill 
holes was the principal cause of defaults in backfilling system (e.g. blocking, wear-induced leakage, and breaking). Settling and blocking mechanism in backfill drill holes was investigated by studying the hydrostatic settlement speed of solids in backfill slurry, settlement hindering of non-spherical particles and settling blocking conditions of slurry aggregate. The water hammer physics model for pressure wave from slurry and water hammer physics model for vacuum bridge of slurry were established. Breaking mechanism of pipelines in backfill drill holes was clarified. Impact wear physics model was set up for vertical backfill holes by analyzing the momentum and energy of backfill slurry. The determination of the breaking location of drill holes was identified and their permanent repairing (as shown in Figure 12) and non-coupling installation of pipelines in backfill holes were also developed. Backfill holes became permanently repairable by the regular cutting and replacing of broken pipelines. Broken drill holes can be refurbished into permanent ones by removing the damaged casing and performing non-coupling installation of backfill pipeline, hence ensuring efficient backfilling.

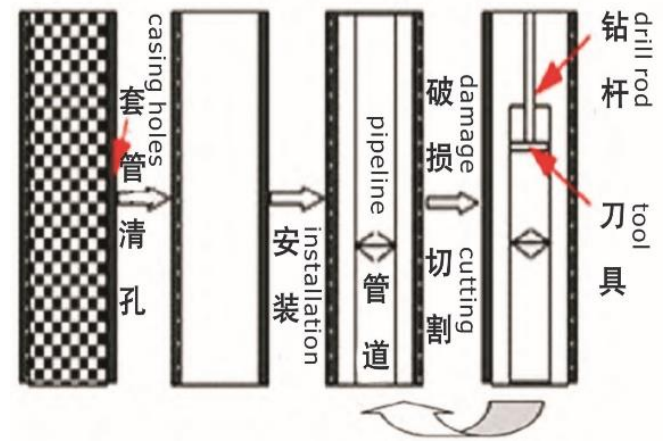

Figure 12 Principle for repairing broken drill holes

\section{$5 \quad$ Conclusions}

Exploitation of Jinchuan Nickel Deposit is faced with a series of major scientific challenges including high ground stress, complex geological structure, mining environment and rock mechanics. For the sake of efficient development and comprehensive utilization of deep resources, previous studies and experiences have been drawn on to innovate the mining engineering theory and technology at the mine.

The mining conditions and rock deformation mechanism at Jinchuan Mine feature high stress and huge deposit reserve. Theories and techniques regarding ground control in stressful and fragmented rocks were developed, laying a foundation for efficient and safe mining in those conditions.

The new technique of large area continuous mining by honeycomb structure drifts was proposed to realise continuous stoping and descending of ore bodies. Mining capacity and profit were significantly increased.

Pipeline transport of high density slurry was developed with solids waste as coarse aggregate. A metal mine was built with state-of-the-art backfilling techniques and parameters as well as the highest backfilling capacity in the world.

A technology package was established for safe and continuous deep mining at the super large and complex Jinchuan Mine, representing a new technical breakthrough in deep mining. The package is not only applied in Jinchuan, but also in a number of mines in China, such as Kalatongke Nickel Mine in Xinjiang Province, Huize Lead-zinc Mine in Yunnan Province and Banmiaozi gold Mine in Jilin Province.

As the mining in Jinchuan Nickel Mine is growing much deeper, more intelligent and towards waste free, in order for an efficient exploitation and comprehensive utilization of deep resources as well as sustainable development, it is significant to investigate the safe, efficient and inexpensive mining methods for deep lean ore resources, to explore the recycling of tailings and smelting slag, to develop large flow backfill slurry with 
huge particle size, to continue researching on the relationship between the law of stress change at mine depth and the response of rock mechanics, and to develop new techniques of deep tunnel support suitable for Jinchuan Mine.

\section{References}

Yang, Z.Q., Gao, Q., Wang, Y.S., Yue, B. Meng, X.H. and Lei, Y. 2013, 'Engineering geology and rock mechanics for super-large nickel mine', Science Publishing House.

He, M.C., 2005, 'Deep conceptual system and engineering assessment index'. Chinese Journal of Rock Mechanics and Engineering, vol. 24 , no. 16 , pp. $2854-2858$

Nonferrous Metal Corporation, 1996, 'Engineering geology and rock mechanics for mining at Jinchuan Mine', Jinchuan Branch of Rock Mechanics and Engineering Association of China.

Nonferrous Metal Corporation, 2000, 'Research on the engineering geomechanics for mining at Jinchuan copper-nickel mine', Geology and Geophysics Institute of Chinese Academy of Science. 